\section{Ileorectal anastomotic obstruction treated with a dual endoscopic transillumination technique}

A 37-year-old woman with refractory constipation underwent a laparoscopic total colectomy with an ileorectal anastomosis. The ileorectal anastomosis was constructed with a circular stapler and protected with a loop ileostomy. Two months later the patient was due to undergo ileostomy closure but fluoroscopic examination showed complete obstruction of ileorectal anastomosis ( $\boldsymbol{\bullet}$ Fig. $\mathbf{1}$ ).

Flexible sigmoidoscopy also revealed a fully obstructed anastomosis, $5-6 \mathrm{~cm}$ from the anal verge. The patient was sedated, and sigmoidoscopy was carried out again with simultaneous antegrade colonoscopy via the caudal side of the loop ileostomy to the level of the ileorectal anastomosis. The anastomotic membrane was transilluminated with the light of the colonoscope ( $\boldsymbol{\bullet}$ Fig. 2 ).

Under this endoluminal illumination, the center of the anastomotic membrane was perforated through the sigmoidoscope with a needle knife (MTW Endoskopie, Wesel, Germany), and a pin-sized hole made on the anastomotic membrane. A balloon catheter (Boston Scientific, Cork, Ireland) was passed via the sigmoidoscope into the anastomotic hole and allowed full dilation of the anastomosis ( $\mathbf{~ F i g . ~ 3 ) . ~}$

Following endoscopic balloon dilatation, a lumen was successfully established (० Fig. 4).

The patient was given perioperative antibiotics and she recovered uneventfully. Two weeks later, she underwent ileostomy closure.

Postoperative anastomotic strictures are generally managed with endoscopic balloon dilatation $[1,2]$. However, as in our case, attempts have been made to treat patients with fully obstructed anastomosis with novel methods. In one patient, a completely occluding anastomotic web was managed with incision and balloon dilatation after dye injection [3]. The dual endoscopic transillumination technique can only be used when a loop stoma is present [4]. In our patient, antegrade colonoscopy through the loop ileostomy was carried out to transilluminate the obstructed anastomosis, which allowed anastomotic dilation.
A dual endoscopic transillumination technique may be used for treatment of selected patients with complete anastomotic obstruction.

\section{Endoscopy_UCTN_Code_TTT_1AQ_2AF}

\section{J. S. Koo' ${ }^{1}$, S. M. Park' ${ }^{1}$ H. J. Yim ${ }^{1}$,}

J. W. Um², H. S. Lee', S. W. Lee',

\section{J. H. Choi ${ }^{1}$}

Division of Gastroenterology, Department of Internal Medicine, Korea University School of Medicine, Seoul, Korea

2 Department of Surgery, Korea University School of Medicine, Seoul, Korea

\section{References}

1 Suchan KL, Muldner A, Manegold BC. Endoscopic treatment of postoperative colorectal anastomotic strictures. Surg Endosc 2003; 17: $1110-1113$

2 Virgilio C, Cosentino S, Favara C et al. Endoscopic treatment of postoperative colonic strictures using an achalasia dilator: shortterm and long-term results. Endoscopy 1995; 27: 219-222

3 Park JW, Sohn DK, Han KS et al. Endoscopic treatment of completely occluding anastomotic web using incision and ballooning after dye injection. Endoscopy 2007; 39 Suppl 10: E102-103

4 Laucks SS 2nd. Method for re-establishing patency of a completely closed colorectal anastomosis. Dis Colon Rectum 1993; 36: 299-300

\section{Bibliography}

Dol $10.1055 / \mathrm{s}-0029-1215220$

Endoscopy 2009; 41: E259

(c) Georg Thieme Verlag KG Stuttgart · New York . ISSN 0013-726X

\section{Corresponding author \\ J. H. Choi}

Division of Gastroenterology

Department of Internal Medicine

Korea University School of Medicine

Ansan Hospital

516 Gojan-dong

Danwon-gu

Ansan-si

Gyeonggi-do 425-707

South Korea

Fax: +82-31-412-5582

kumccjh@ns.kumc.or.kr

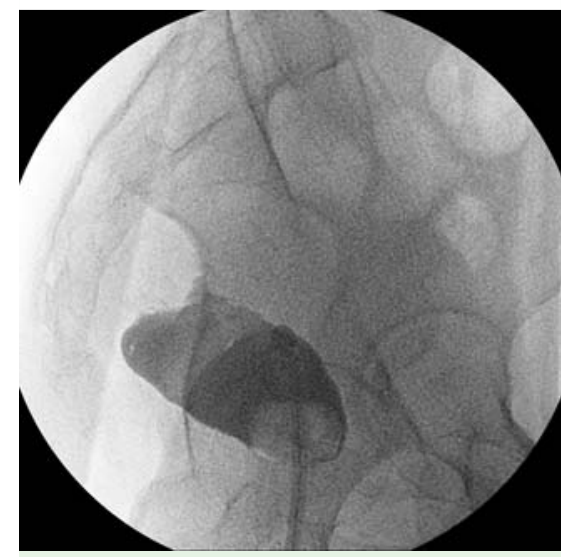

Fig. 1 Barium enema showing complete obstruction of the ileorectal anastomosis.

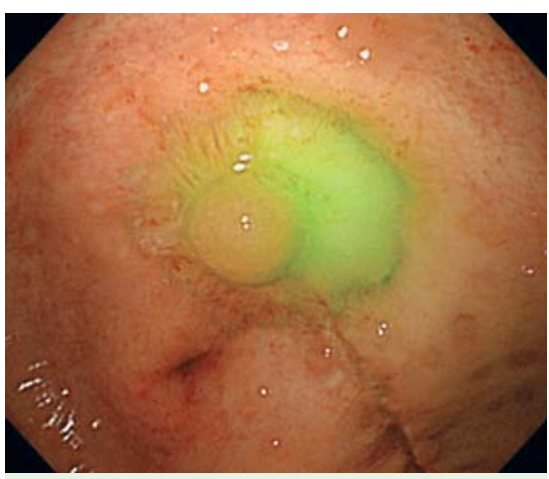

Fig. 2 Transillumination of the obstructed ileorectal anastomosis, using a colonoscope.

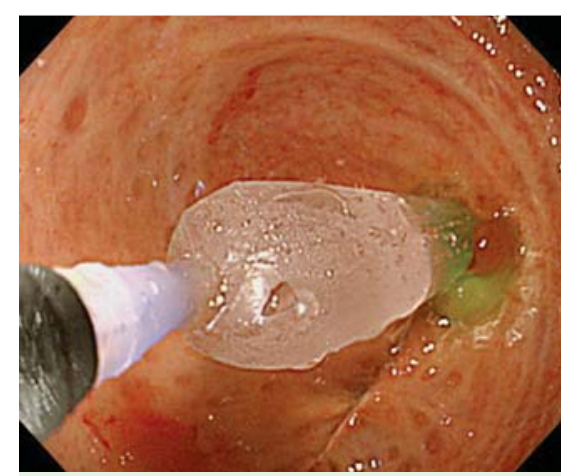

Fig. 3 "Through-the-scope" balloon dilation of the ileorectal anastomosis.

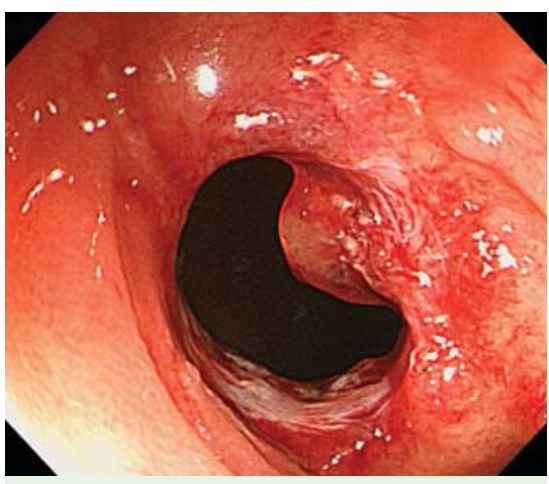

Fig. 4 Endoscopic view of the anastomosis immediately after dilation. 